\title{
Parâmetros ósseos de frangos de corte alimentados com rações contendo fitase e baixos níveis de fósforo disponível e proteína bruta
}

\author{
[Bone parameters for broilers fed diets with phytase and low phosphorus \\ and crude protein levels] \\ A.C.N. Vaz ${ }^{1}$, R. Albuquerque ${ }^{2}$, M.L. Brisola ${ }^{3}$, D.C.Z. Donato ${ }^{4}$, P.D.S.R. Garcia ${ }^{4}$ \\ ${ }^{1}$ Aluno de pós-graduação - Faculdade de Zootecnia e Engenharia de Alimentos - Universidade \\ de São Paulo - São Paulo, SP \\ ${ }^{2}$ Faculdade de Medicina Veterinária e Zootecnia - Universidade de São Paulo - São Paulo, SP \\ ${ }^{3}$ Faculdade de Medicina Veterinária - Pontifícia Universidade Católica de Minas Gerais - Poços de Caldas, MG \\ ${ }^{4}$ Aluno de pós-graduação - FCAV/Unesp - Jaboticabal, SP
}

\begin{abstract}
RESUMO
Foram utilizados 504 pintos de linhagem comercial (Ag Ross 308) para frangos de corte de um dia de idade, distribuídos em 12 tratamentos com seis repetições. O delineamento experimental utilizado foi de blocos ao acaso em esquema fatorial $2 \times 2 \times 3$, com dois níveis de fósforo disponível $(0,45$ e $0,34 \%)$, dois níveis de fitase ( 0 e $1200 \mathrm{FTU} / \mathrm{kg}$ ) e três níveis de proteína bruta $(22,5 ; 20,5$ e 18,5\%). A porcentagem de cálcio e fósforo nas tíbias foi influenciada significativamente pelos níveis de proteína e de fósforo na dieta com o uso da fitase. Os teores de matéria mineral nas tíbias apresentaram efeito linear com o uso da enzima e efeito quadrático com a ausência dela, apresentando maior valor com o nível de 22,5\% de proteína na dieta. Já com os maiores níveis de fósforo houve efeito linear entre os níveis de proteína bruta na dieta e os pesos da matéria mineral nas tíbias, ou seja, quanto maior o nível de proteína, menor o peso da matéria mineral.
\end{abstract}

Palavras-chave: avicultura, cálcio, enzima, matéria mineral, tíbia

\begin{abstract}
504 (five hundred four) 1 day old male chicks from a commercial broiler line (Ag Ross 308) were used, distributed in 12 treatments, with 6 replicates per treatment. The experimental design was casually blocked and treatments were organized in a 2x2x3 factorial arrangement: two available phosphorus levels (0.45 and 0.34\%), two phytase inclusion levels (0 and $1200 \mathrm{FTU} / \mathrm{kg}$ ) and three crude protein levels (22.5; 20.5 and 18.5\%). Tibia calcium percentage was influenced by protein and phosphorus levels in the diet, when using phytase. Tibia ash levels showed a linear effect when enzymes were added and showed a quadractic effect without it, and the higher value was observed with $22.5 \%$ crude protein in the diet. With higher phosphorus levels a linear effect was observed between crude protein in the diet and tibia ash weights, as a higher protein level had lower tíbia ash weight.
\end{abstract}

Keywords: poultry, calcium, enzyme, ashes, tibia

\section{INTRODUÇÃO}

A avicultura é uma atividade econômica que desempenha papel de grande importância na estrutura agropecuária do Brasil, sendo um constante desafio para os técnicos obterem maior produtividade com menores custos (Brandão et al., 2007). O fósforo é indicado como o terceiro nutriente mais caro em uma ração, atrás somente da energia e da proteína. Ele também está entre os minerais mais exigidos pelas aves, dada a sua necessidade, não apenas para a ótima taxa de

Recebido em 20 de março de 2012

Aceito em 11 de março de 2013

E-mail: acnvaz@usp.br

Apoio financeiro: Fundação de Apoio à Pesquisa - Estado de São Paulo - FAPESP, TORTUGA e BASF 
crescimento, mas também para a mineralização óssea (Laurentiz et al., 2007). A enzima fitase pode melhorar o aproveitamento de nutrientes, provavelmente permitindo diminuição dos níveis de proteína e fósforo disponível adicionados às dietas, sem interferir no desempenho e na composição óssea das aves. O presente trabalho tem como objetivo avaliar o efeito da adição da enzima fitase, associada a baixos níveis de fósforo disponível e proteína bruta, sobre os parâmetros ósseos de frangos de corte de um a 21 dias de idade.

\section{MATERIAL E MÉTODOS}

O trabalho foi conduzido no aviário experimental do Departamento de Nutrição e Produção Animal da Faculdade de Medicina Veterinária e Zootecnia da Universidade de São Paulo. Foram utilizados 504 pintos de corte, machos, Ag Ross 308 , de um a 21 dias de idade e peso inicial médio de $42 \mathrm{~g}$. As aves foram alojadas em gaiolas de aço inoxidável $(1,0 \mathrm{~m} \times 0,4 \mathrm{~m})$, dispostas em três baterias de seis andares, equipadas com aquecimento elétrico, comedouro, bebedouro tipo nipple e bandeja, também de aço inoxidável $(0,9 \mathrm{~m} \times 0,32 \mathrm{~m})$, para coleta de excretas.

As rações (Tab. 1) foram isonutritivas, exceto para os níveis de proteína bruta e fósforo disponível, à base de milho e farelo de soja, com formulação que atendia aos níveis nutricionais recomendados por Rostagno et al., 2005. As aves receberam água e ração à vontade. As dietas calculadas continham dois níveis de fósforo disponível $(0,45$ e $0,34 \%)$, dois níveis de fitase (0 e $1200 \mathrm{FTU} / \mathrm{kg}$ ) e três níveis de proteína bruta $(22,5 ; 20,5$ e $18,5 \%)$. A enzima fitase utilizada foi da marca comercial Natuphos®, da BASF, com atividade de 1200 FTU/kg de ração.

Ao final dos 21 dias, duas aves de cada unidade experimental foram abatidas por deslocamento cervical, e as tíbias direitas removidas e descarnadas sem injúria de osso e cartilagem, identificadas, embaladas e levadas ao congelador a $-20^{\circ} \mathrm{C}$ para determinação de cinzas e fósforo (Associatoin..., 1980).

O delineamento experimental utilizado foi de blocos ao acaso, em esquema fatorial $2 \times 2 \times 3$, com seis repetições e sete aves por unidade experimental. Os dados foram submetidos à análise de variância e, com base nesta análise, foram realizados testes de regressão entre os níveis de proteína bruta e as variáveis, respeitando-se a presença ou não das interações. O programa estatístico utilizado foi o SAS (Statistical..., 1990).

Este trabalho foi aprovado em 22/08/2007 pelo Comitê de Bioética da Faculdade de Medicina Veterinária e Zootecnia da Universidade de São Paulo, protocolado sob o ${ }^{\circ}$ 1171/2007.

Tabela 1. Composição (\%) das dietas experimentais

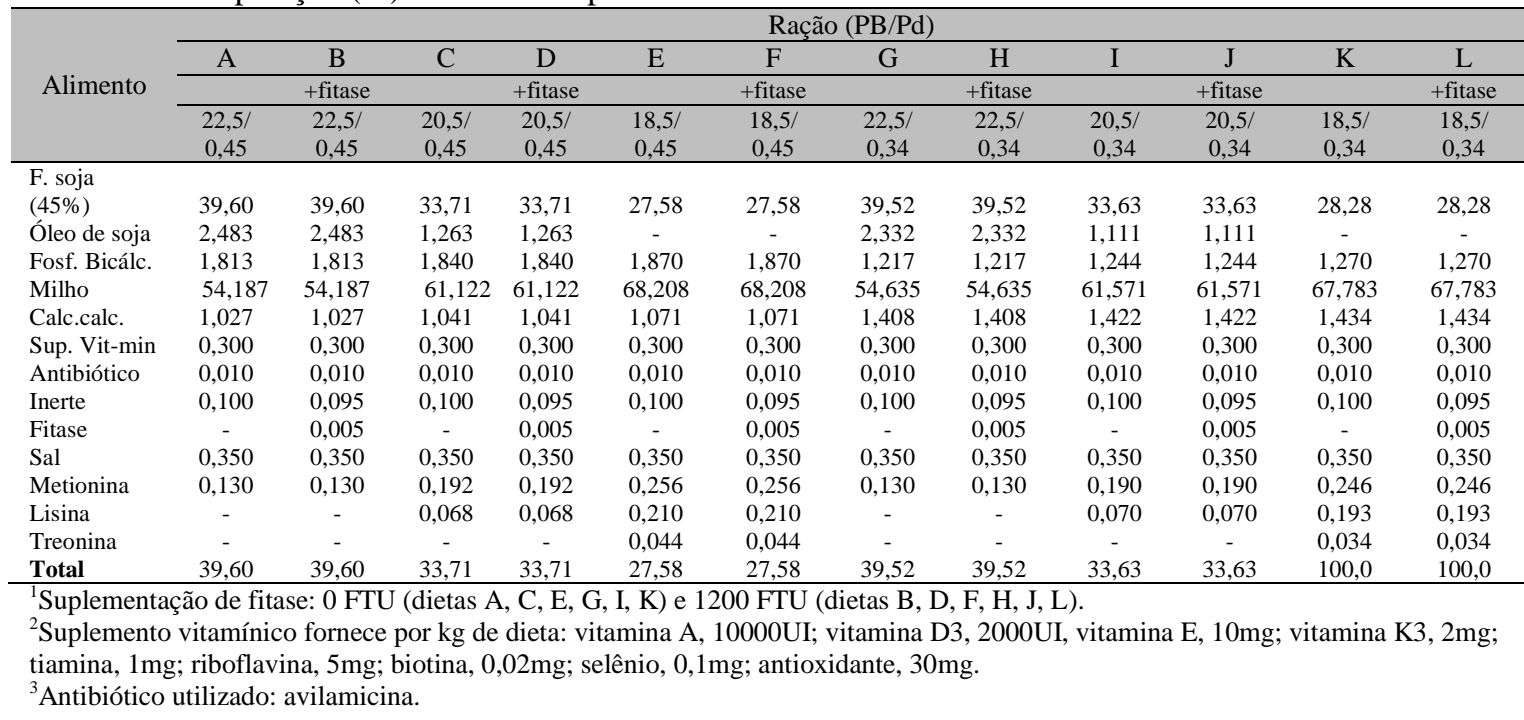




\section{RESULTADOS E DISCUSSÃO}

Os valores de porcentagem de cálcio na tíbia podem ser encontrados na Tab. 2, de acordo com os níveis de fósforo disponível, proteína bruta e fitase. Houve efeito significativo somente dos níveis de proteína sobre a porcentagem de cálcio na tíbia. Com o aumento no nível de proteína, houve diminuição da porcentagem de cálcio (efeito linear, $\mathrm{P}<0,05$ ). A média geral de porcentagem de cálcio na tíbia nos tratamentos com e sem fitase foram, respectivamente, de 9,91 e $10,04 \%(\mathrm{P}>0,05)$. Este resultado difere dos resultados encontrados por Zanini e Sazzad (1998), que, ao avaliarem o efeito da suplementação da fitase sobre a utilização mineral, observaram um aumento na concentração de cálcio e zinco na tíbia de pintos de corte. Na média geral dos tratamentos, em relação aos níveis de fósforo disponível $(0,34$ e $0,45 \%$ ), observa-se um aumento na porcentagem de cálcio no nível mais alto de fósforo disponível. Este aumento (9,52 vs. 10,39\%) apresentou diferença estatística significativa ( $\mathrm{P}<0,05)$. Ahmad et al. (2000), ao estudarem dietas contendo milho e farelo de soja na ausência ou presença de fitase (1075 FTU/kg), observaram aumento na concentração de fósforo e cálcio na tíbia. A análise estatística desses dados gerou um coeficiente de variação de $13,34 \%$.

Tabela 2. Matéria mineral (g), cálcio e fósforo (\%) da tíbia (média \pm desvio-padrão) por níveis de fitase, de fósforo e de proteína na dieta

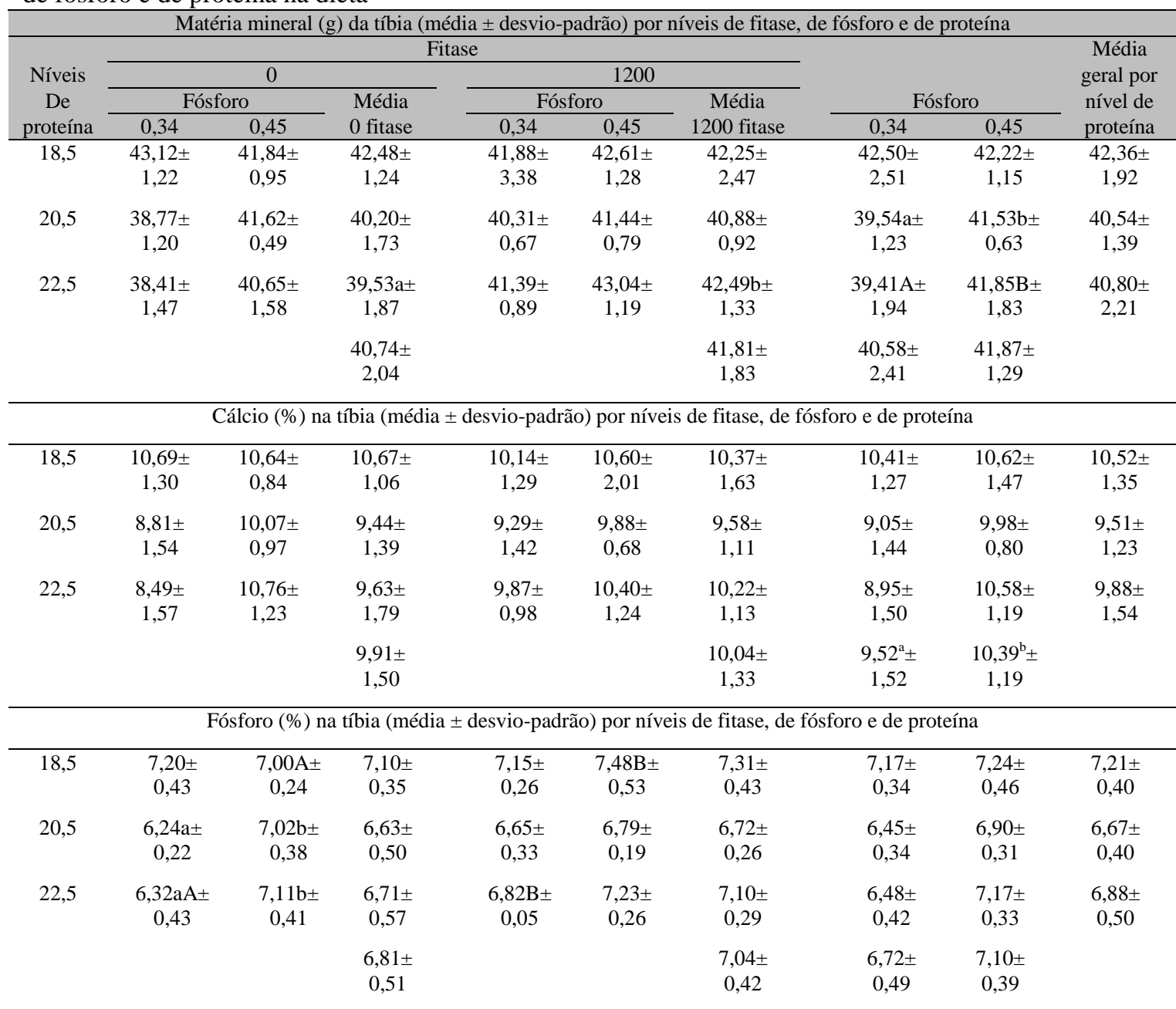

Médias na linha com letras minúsculas diferentes diferem significativamente $(\mathrm{P}<0,05)$ pela análise de variância. Médias na linha com letras maiúsculas diferentes diferem significativamente $(P<0,05)$ pela análise de variância. 
Sem o uso de fitase, os teores de fósforo da tíbia foram maiores $(\mathrm{P}<0,05)$ quando o nível de fósforo disponível na dieta foi o mais alto $(0,45 \%)$ e com os maiores teores de proteína bruta (20,5 e $22,5 \%)$, o que não ocorreu quando havia suplementação de fitase, indicando um possível efeito da enzima na deposição óssea do mineral (Tab. 2). No nível mais baixo de fósforo disponível $(0,34 \%)$ e no mais alto de proteína bruta $(22,5 \%)$, o percentual de fósforo na tíbia foi maior na presença da fitase $(\mathrm{P}<0,05)$, assim como com o mais alto nível de fósforo disponível $(0,45 \%)$ e o menor de proteína bruta na dieta $(18,5 \%)$, o percentual de fósforo na tíbia foi maior com a suplementação da enzima, reforçando a hipótese do efeito da fitase na concentração de fósforo na tíbia, que a aumentou. Estes resultados corroboram os de Runho et al. (2001), que observaram maior deposição de fósforo no osso $(6,81 \%)$ quando se elevou o nível de fósforo disponível da dieta até o nível de $0,45 \%$, tanto para machos como para fêmeas. Com base na análise de regressão, observou-se efeito quadrático para o tratamento com $0,34 \%$ de fósforo, sem adição de fitase, e para o tratamento com $0,45 \%$ de fósforo com adição de fitase, com o tratamento com 18,5\% de proteína bruta apresentando as maiores concentrações de fósforo na tíbia $(\mathrm{P}<0,05)$. No presente trabalho, não houve efeito do nível de fósforo disponível na dieta sobre o percentual de fósforo na tíbia com a suplementação da enzima, mas, na ausência desta, houve efeito significativo, corroborando o observado por Laurentiz et al. (2007), os quais concluíram que a diminuição do nível de fósforo disponível na dieta $(0,41$ vs. $0,17 \%)$ na fase de crescimento interfere de forma negativa na porcentagem deste na tíbia, embora o menor nível de fósforo disponível no presente trabalho tenha sido o dobro $(0,34$ vs. $0,17 \%)$ do utilizado por aqueles autores, sendo que a análise dos dados deste estudo resultou num coeficiente de variação igual a $5,16 \%$.

Os valores de peso da matéria mineral da tíbia podem ser visualizados na Tab. 2. Os valores estão expressos em gramas, de acordo com os níveis de fitase, fósforo disponível e proteína bruta. $\mathrm{O}$ coeficiente de variação do modelo foi bem reduzido $(3,50 \%)$. A presença da fitase aumentou significativamente o peso da matéria mineral da tíbia quando foi utilizado o nível de $22,5 \%$ de proteína $(\mathrm{P}<0,05)$, sendo que, na ausência da fitase, houve um efeito linear $(\mathrm{P}<0,05)$, ou seja, com o aumento da proteína bruta na dieta, houve redução no peso das cinzas, enquanto na presença da enzima houve um efeito quadrático $(\mathrm{P}<0,05)$, isto é, com o menor e com o maior nível de proteína bruta na dieta, os pesos da matéria mineral foram mais elevados. Isto pode ser um indicador do efeito da fitase sobre o total de minerais nos ossos, assim como foi observado com a porcentagem de fósforo na tíbia. A concentração de fósforo disponível na dieta também influenciou o peso da matéria mineral na tíbia $(\mathrm{P}<0,05)$, pois, nos tratamentos com os maiores níveis de proteína bruta $(20,5$ e $22,5 \%$ ), os pesos foram maiores com o maior nível de fósforo disponível na dieta $(0,45 \%)$. Com $0,34 \%$ de fósforo disponível na dieta, houve efeito linear significativo $(P<0,05)$ entre $o$ peso da matéria mineral na tíbia e o teor de proteína bruta na dieta, ou seja, quanto maior a proteína bruta, menor o peso das cinzas $(\mathrm{P}<0,05)$. A provável relação entre a suplementação de fitase na dieta de aves e o peso da matéria mineral na tíbia encontrada neste trabalho já foi observada por outros autores. Ao estudarem o efeito de enzimas associadas a uma dieta contendo $40 \%$ menos fósforo disponível que o recomendado sobre as características ósseas de frangos de corte, Conte et al. (2003) observaram que os níveis crescentes de fitase $(0,400,800$ e $1200 \mathrm{FTU} / \mathrm{kg}$ ) promoveram aumento linear nos teores de cinzas das tíbias, e estes não afetaram a deposição de ferro $(\mathrm{Fe})$, cobre $(\mathrm{Cu})$, zinco $(\mathrm{Zn})$ e manganês (Mn). Tais resultados podem ser confirmados por Hall et al. (2003), que, ao utilizarem frangos de corte machos de um a 21 dias de idade, demonstraram efeito da adição de diferentes níveis de fitase $(0,750,1500,3000$ e $6000 \mathrm{FTU} / \mathrm{kg}$ ) em uma dieta à base de milho e farelo de soja na mineralização óssea das aves. Essa interação também foi observada por Kasim et al. (2000), os quais, ao estudarem os efeitos da fitase sobre diferentes tamanhos e fontes de milho na dieta de frangos de corte, relataram que a adição de fitase (600 FTU/kg) em todos os tratamentos levou a um aumento da matéria mineral dos ossos. O mesmo efeito foi observado por Dilger et al. (2004), ao avaliarem a fitase microbiana (500 e $1000 \mathrm{FTU} / \mathrm{kg}$ ) em rações para frangos de corte. Dietas com baixo fósforo disponível e adição de fitase em nível 32\% menor que o recomendado (290 FTU/kg vs. 900 FTU/kg) mostraram efeitos positivos na relação 
de matéria mineral na tíbia, conforme foi demonstrado por Ribeiro et al. (2003).

\section{CONCLUSÃO}

A atuação da enzima depende dos níveis de fósforo disponível e de proteína bruta na dieta, sendo que a utilização de maiores níveis proteicos dietéticos na dieta de frangos de corte pode ocasionar uma redução na deposição de fósforo na tíbia de aves. Este efeito é minimizado com a suplementação da enzima fitase, sem que esta afete as porcentagens de deposição de cálcio nos ossos das aves.

\section{REFERÊNCIAS}

AHMAD, T.; RASOOL, S.; SARWAR, M. et al. Effect of microbial phytase produced from a fungus Aspergillus niger on bioavailability of phosphorus and calcium in broiler chickens. Anim. Feed Sci. Technol., v.83, p.103-114, 2000.

ASSOCIATION Of Official Analytical Chemistis - AOAC. Official methods of analysis. 11.ed. Washington, D.C., 1980. 1051p.

BRANDÃO, P.A.; COSTA, F.G.P.; BRANDÃO, J.S. et al. Efeito da adição de fitase em rações de frangos de corte, durante as fases de crescimento e final. Cienc. Agrotec., v.31, p.492-498, 2007.

CONTE, A.J.; TEIXEIRA, A.S.; FIALHO, E.T. et al. Efeito da fitase e xilanase sobre o desempenho e as características ósseas de frangos de corte alimentados com dietas contendo farelo de arroz. Rev. Bras. Zootec., v.32, p.1147-1156, 2003.

DILGER, R.N.; ONYANGO, E.M.; SANDS, J.S. et al. Evaluation of microbial phytase in broiler diets. Poult. Sci., v.83, p.962-970, 2004.

HALL, L.E.; SHIRLEY, R.B.; BAKALLI, R.I. et al. Power of two methods for the estimation of bone ash of broilers. Poult. Sci., v.82, p.414-418, 2003.
KASIM, A.B.; EDWARDS JR., H.M. Effect of sources of maize and maize particle sizes on the utilization of phytate phosphorus in broiler chicks. Anim. Feed Sci. Technol., v.86, p.15-26, 2000 .

LAURENTIZ, A.C.; JUNQUEIRA, O.M.; FILARDI, R.S. et al. Efeito da adição da enzima fitase em rações para frangos de corte com redução dos níveis de fósforo nas diferentes fases de criação. Cienc. Anim. Bras., v.8, p.207-216, 2007.

RIBEIRO, A.M.L.; MIRELES, A.J.; KLASING, K.C. Interactions between dietary phosphorus level, phytase supplementation and pelleting on performance and bone parameters of broilers fed high levels of rice bran. Anim. Feed Sci. Technol., v.103, p.155-161, 2003.

ROSTAGNO, H.S.; ALBINO, L.F.T.; DONZELE, J.L. Tabelas brasileiras para aves $e$ suínos: composição de alimentos e exigências nutricionais. Viçosa (MG): Horácio Rostagno, 2005. 141p.

RUNHO, R.C.; GOMES, P.C.; ROSTAGNO, H.S. et al. Exigências de fósforo disponível para frangos de corte machos e fêmeas de 1 a 21 dias de idade. Rev. Bras. Zootec., v.30, p.187-196, 2001.

STATISTICAL Analysis System - SAS. User's guide: statistics. Cary: N.C., 1990. (Realease $6.04 \mathrm{Ed}$.)

ZANINI, S.F.; SAZZAD, M.F. Efeito da adição de fitase em dietas com dois níveis de energia metabolizável para pintos de corte. Arq. Bras. Med. Vet. Zootec., v.50, p.611-618, 1998. 